\title{
INFORME SOBRE UN NÚMERO DE ESCULTURAS DE PIEDRA DE COSTA RICA
}

\author{
(BERICHT ÜBER EINE ANZAHL \\ STEINSCULPTUREN AUS COSTARICA)
}

\author{
Heinrich Fischer \\ Friburgo, Alemania
}

Traducción al español:

Oscar H. Lücke ${ }^{1}$ \& Guillermo E. Alvarado ${ }^{2}$

\author{
${ }^{1}$ Escuela Centroamericana de Geología, Universidad de Costa Rica \\ ${ }^{2}$ Área de Amenazas y Auscultación Sísmica y Volcánica (A3SV), Instituto \\ Costarricense de Electricidad
}

\section{Tomado del original Bericht über eine Anzahl Steinsculpturen aus Costarica, Abhandlungen herausgegeben vom naturwissenschaftlichen \\ Verein zu Bremen, 7: 153-185}

En los más variados museos públicos así como en colecciones privadas se encuentran dispersas obras de arte provenientes de México, Centro y Sudamérica, las cuales hasta el momento solo han sido posicionadas a manera de piezas de exhibición incomprendidas. Ya es tiempo de que estas piezas sean sometidas a pruebas científicas secuenciales desde todo punto de vista. De hecho debe uno preguntarse, ¿por qué esto ha sido omitido por tanto tiempo?

Podríamos entonces encontrar la razón para esta omisión, al menos en parte, en los programas de estudio de nuestros colegios humanísticos en los cuales, cuando se trata el tema de la antigüedad fuera de Europa, por encima de todo se habla de los egipcios, asirios, etc. Hasta donde yo sé, falta de igual manera una labor en la que por ejemplo, se determine el significado que pequeñas esculturas de esmalte egipcias tenían en el contexto de su tierra de proveniencia original. No debe sorprender entonces al lector de esta revista, que las esculturas de las civilizaciones americanas antiguas, se encuentren envueltas en el más profundo misterio debido a que en las escuelas superiores se trata muy poco el tema de estas naciones.

Después que desde hace dos décadas mi completa atención girara alrededor de este tema de discusión y de haberme dedicado principalmente 
a una serie de trabajos ${ }^{1}$ provistos con ilustraciones, fui informado a través de un amigo, acerca de la existencia de esculturas de piedra ${ }^{2}$ originadas en Costa Rica, las cuales se encuentran en museos de historia natural y etnografía del estado de Bremen. El señor Dr. Huber Ludwig fue el director de estas instituciones, quien con gusto a partir de mi petición, me ha facilitado estos 63 objetos para trabajar con ellos.

Aquellas colecciones que, como en el caso expuesto a continuación, solo contienen objetos provenientes de un área específica, son especialmente adecuadas para explicar la presencia de algún atributo característico que no se encuentre en ningún otro país, ya sea que involucre el material, la forma o la manera de trabajar las piezas. $\mathrm{Al}$ menos debería ser posible a partir de la repetición de formas específicas, encerrar dentro de provincias limitadas a cierto artista o escuelas de arte. Así que esto también es aplicable aquí hasta cierto grado.

No me he encontrado hasta este momento con algo como las figuras-amuleto similares a hachas planoconvexas de Centroamérica. Por ejemplo las mostradas en las láminas X y XI, Figs. 22, $23,24,25$, y que yo ya había retratado en la obra titulada "Trabajos en nefrita" (en las que el ahora difunto Dr. Von Franzius tomó parte en las ilustraciones pág. 344, Fig. 121 a.b. y 122 a.b. al lado de las Fig. 35 a.b. y 34 a.b. que se encuentran ahora en el museo de Friburgo).

La parte trasera plana muestra en todos los ejemplares de esta forma-tipo, una superficie lisa aserrada en el medio con una áspera y estrecha banda caracterizada por marcas de fracturas y no por sierra. Estas piezas de roca fueron trabajadas a partir de un bloque mediante una sierra hasta que la unión llegara a ser estrecha y pudiese ser completamente separado fracturándolo. El medio para aserrar aparenta ser arena, agua y un objeto delgado (tendones, filamentos duros de plantas u otro objeto similar), no mediante instrumentos planos. Las superficies son arqueadas, torcidas, si se quiere decir, como si se hubiesen querido a propósito ajustar poco mediante instrumentos planos como hojas de sierra. La fractura final del estrecho puente de unión no es violenta, sino interponiendo cuñas de madera y luego siendo sumergido en agua; bajo esta suposición, es posible aceptar que el artista trabajó primero en la base compacta de toda la pieza de roca y luego aserró la figura; sin embargo, todas las estrechas figuras de roca estarían después de todo en peligro durante el aserrado. Por lo tanto, debió haber sido más probable que la forma general de la escultura y el trabajo con la sierra estuviesen terminados antes de que el artista comenzara con la elaboración del grabado de las líneas ${ }^{3}$.

Yo encontré que en estas figuras costarricenses, la perforación media para el colgante mediante un hilo es completamente igual a las encontradas en figuras mexicanas. La figura 258 en la lámina IX muestra 3 distintas direcciones de perforación al mismo tiempo, vertical (en a), horizontal (en b) e inclinada (submarginal; en c).

En lo que concierne al material, se trata de simples minerales: cuarzo variedad calcedonia, - heliotropo en conjunto con ópalo verde oscuro (?), nontronita (?), prehnita (?), serpentina (?), arcilla, Strahlstein [actinolita en agregados radiales], jadeíta, feldespato (sanidina?); fueron identificados los siguientes tipos de roca: arcillolita silicificada (Wetzschiefer)(?), esquisto micáceo, fonolita (?), andesita con anfíboles (?), dolerita.

Como anteriormente se observa, algunos diagnósticos debieron ser puestos en duda. Es decir, no puede ser en todo caso, que el trabajo de la mineralogía arqueológica aspire a la determinación exacta del material sin importar el costo a las formas de los pequeños objetos. Es suficiente, para el objetivo presente, llegar a un diagnóstico aproximado.

El ensayo que yo aplico primero es la determinación del peso específico ${ }^{4}$. No solo en el caso de los minerales, sino también para los tipos de roca cristalina, que en el marco de estas sustancias en las que se ha pensado en casos particulares, este ensayo es muy determinante y permite llegar rápidamente a un objetivo aproximado.

En relación con los artefactos de jadeíta, como yo ya lo he explicado y enfatizado en una serie de publicaciones anteriores ${ }^{5}$, que tanto en América como en Europa hasta el momento se conoce muy poco acerca de la ocurrencia natural de las variedades de colores de estos tenaces minerales con dureza similar al cuarzo; por lo tanto, se debe hacer énfasis en la idea de la posibilidad 
de que las culturas americanas hayan tenido acceso a minerales como nefrita, cloromelanita y otros, los cuales solo se conocen en Asia, a través de vías de comercio con los tan mal percibidos conquistadores españoles cristianos.

Para las esculturas de jadeíta, yo conozco debido a mis relaciones con Asia, acerca de la existencia de ricas materias primas asiáticas idénticas, asimismo soy capaz de especificar la presencia de estos materiales en todos los objetos de nefrita como recientemente la variedad verdeamarilla de los ídolos de ranas de Ginebra (nefrita y otros a.a.O. pág. 33, Fig. 38) y de los largos bastones (pág. 29, Figs. 24 y 25).

En la colección del Museo de Bremen, los objetos de jadeíta $\mathrm{N}^{\circ} 111$ y $\mathrm{N}^{\circ} 112$ se caracterizan por su confección muy pulida y brillante y su profundo color azul-zafiro. La coloración verdosa es poco frecuente. Esta es, junto con la variedad verde-esmeralda, una de las variedades más bellas de la jadeíta. Yo recuperé en Paris, una variedad idéntica de jadeíta proveniente de China, la cual había sido pasada desde Birmania mediante el comercio. A partir de un crudo pedazo del mineral procedente del yacimiento anterior, yo corté y pulí un pedazo en forma de cuña en la marmolería del Sr. Trenkle ubicada en Waldkirch en los alrededores de Friburgo, lo coloqué al lado de los objetos costarricenses del Museo de Bremen y estos muestran una sorprendente concordancia en el color.

Asimismo, puedo constatar la procedencia del mismo yacimiento de Indochina, tanto para las perlas mexicanas de jadeíta color verde-esmeralda que se encuentran en el Museo de Friburgo, Copenhague y otros, como para las distintas cuñas prehistóricas de jadeíta que se encuentran en Europa.

La mayor cantidad de materia prima de jadeíta proveniente de Birmania, la obtuve recientemente mediante los señores Conde Bela Szechenyi de Zinkendorf (Hungría) y el ingeniero-geólogo Ludwig Loczy en Budapest, quienes durante sus viajes a Asia han dedicado en una manera digna del mayor agradecimiento a su sabiduría, su completa y especial atención a los minerales de jadeíta y nefrita de importancia histórica, quienes han puesto a mi libre disposición, los ejemplares encontrados.
Nosotros debemos poner frente a nuestros ojos, el hecho de que cientos de ejemplares de jadeíta cambiaron de manos durante el tiempo prehistórico de Europa y América además durante la antigüedad egipcia. Estos ejemplares se encuentran en alrededor de 20 variedades y en estados distintos de fabricación (ídolos, hachas etc.), matices de color y fineza textural. Además, a mí me ha llegado una cantidad de piezas de distintas variedades de jadeíta en bruto para la colección de nuestro museo, no solo provenientes de Indochina o a través de investigadores húngaros, sino también una cantidad similar obtenida indirectamente desde China debido a una buena mediación del servicio diplomático imperial alemán, mientras que se debe hacer énfasis que mientras el intercambio ocurría, no se conoce la existencia en otra región, por ejemplo en India, ni de un solo gramo de jadeíta en bruto o como componente de la roca. A partir de estos hechos y las nociones humanas generales, además de las experiencias científicas de la mineralogía, se concluiría que todos los objetos prehistóricos de jadeíta provenientes de distintas partes del mundo, tienen su origen en Asia y hasta donde nosotros sabemos, en Indochina, mientras que al ser poco probable todo lo anteriormente mencionado, se piensa en la posibilidad de la existencia de un yacimiento de jadeíta no trabajada a gran escala en Europa y América, el cual haya sido explotado y agotado por personas prehistóricas y a tal grado que en el presente no se encuentre este mineral ni en las cordilleras ni en ríos a manera de rodados. Se sabe que en el presente, la jadeíta y la nefrita juegan un papel importante en China como piedras preciosas y piedras para joyería, de la misma manera que en Europa y América en tiempo prehistórico.

Veamos ahora la relación análoga en la antigüedad egipcia con respecto a las piedras preciosas y ornamentales. Se conocen ya con exactitud los sitios en Arabia y Persia en los cuales ya en ese tiempo se explotaba la kallaíta (turquesa), al igual que amazonita y malaquita, estos últimos minerales se obtenían de lugares lejanos (Siberia?).

El yacimiento de ninguno de los minerales anteriormente mencionados, inclusive la lazurita, es tan grande como el de la jadeíta, de la cual se 
han descubierto en Europa hachas de 1 a 2 pies de largo y que solo a mí me han presentado alrededor de 16000 gramos de este mineral para examinarlo y que un único joyero parisino en unos cuantos años ha llevado a Paris alrededor de 1000 kilogramos con propósitos ornamentales.

Después de estas consideraciones generales iniciales, se debe tratar el tema de la forma de las antigüedades del museo de Bremen. Entre las formas de los ornamentos se encuentran esferas, cilindros y óvalos, que cuelgan de una cuerda a manera de piezas de collares perforadas a lo largo. Esto presenta similitud con los objetos de egipcios, asirios persas y de Asia Menor, los cuales de vez en cuando se encuentran asociados con el oro, que para las piezas costarricenses no es el caso.

Algunos objetos de jadeíta por ejemplo los de la lámina VII, $\mathrm{N}^{\circ} 257,110,111,112,113,114$, pudieron haber sido parte de las empuñaduras de cuchillos, cinceles o hachas, o simplemente fueron objetos de culto o de adorno debido a que el material era tan costoso y a que los bordes cortantes no presentan daño ni desgaste $-\mathrm{N}^{\circ} 261$ se considera como un punzón, $\mathrm{N}^{\circ} 125$ y 126 podrían haber sido utilizados para la molienda del maíz.

Una serie de otros objetos se presentan sin ninguna duda a modo de piezas que formaban parte de representaciones ya sea de cabezas de animal o de cuerpos enteros de animales. A partir de las esculturas que han pasado por mis manos y también de las hachas pulidas, ha sido posible reconocer que las civilizaciones antiguas utilizaban de manera casi exclusiva, cantos rodados de riachuelos y ríos.

En caso de tener una idea de la forma del objeto que se iba a fabricar, entonces se buscaba un rodado con la forma más apropiada. De otra manera, debió ocurrir de vez en cuando que el rodado ya presentaba a priori una forma y dependiendo de esta, se cincelaba la forma de uno u otro animal. De otra manera, en los casos particulares como el $\mathrm{N}^{\circ} 200$, probablemente se modificaba un poco artísticamente o solo se fabricaba un orificio para colgar.

Relacionado con estos agujeros para cuerda, como los llamaremos de ahora en adelante, es muy fácil no darles una atención adecuada y en primera instancia confundirlos con los ojos del animal representado. Sin embargo, estos agujeros para cuerda no representan los ojos. Por ejemplo en la Fig. 302, lámina VII, que representa un pez, es posible apreciar claramente que delante de los agujeros para cuerda existe una superficie hundida que corresponde con los ojos. Es solo cuando se tiene en frente una lista de los animales que viven en Costa Rica, la cual en este momento no poseo, que se puede decir, aunque de manera difícil, si la escultura en algunos casos (por ejemplo: $\mathrm{N}^{\circ} 184$, $171,175,253$ en la lámina IX y VIII) representa un animal o solo un ornamento dentado ideado a voluntad por el artista. Esto se enfatiza cuando se tiene en cuenta la inclinación de las figuras antropomórficas mexicanas y centroamericanas hacia la ornamentación fantástica y recargada, también presente en las figuras de animales. Esto lleva a la posibilidad de que las esculturas se originen a partir del reino de la fantasía. Además, se debe tener en cuenta los métodos muy primitivos de trabajo de estos minerales, por ejemplo el cuarzo y otros, que presentan una dureza tan alta. Esto lleva a pensar que la forma resultante del trabajo final depende también de la forma original del canto rodado que fue modificado por el artista con el permiso otorgado de coterráneos y contemporáneos camaradas, para no copiar fielmente las formas de la naturaleza.

De aquí en adelante, en aquellos casos en los que se trate sin duda de un animal, no se debe creer que se tiene una duda en cuanto a que si se trata de un mamífero o un ave, o un mamífero o un reptil. Sino que uno se ha encontrado con deficiencias en las características de las formas. Eso cree la mayoría de observadores a quienes les muestro la figura $\mathrm{N}^{\circ} 167$, lámina VIII, en la cual algunos observadores interpretan los agujeros para cuerda como si fuesen los ojos y los colocan hacia atrás y de esta manera reconocen que se trata de cálao (de la familia Bucerotidae) mientras que otro observador, coloca los agujeros para cuerda hacia adelante e interpreta en su totalidad un conejo acostado ("Tochtli" para los mexicanos) con sus orejas retiradas hacia atrás de la cabeza. En este caso, ninguna de las opiniones confirma a la otra.

En relación con el $N^{\circ} 173$ lámina VII, se puede entrar en duda en cuanto a si se considera la colocación hacia abajo o hacia arriba del apéndice sinuoso similar a un pico, y también que en este caso se considera a los agujeros para cuerda como 
los ojos. A partir de esta suposición, se puede pensar en un saltamontes del género Tryxalis.

Surgen varias dudas acerca de los surcos verticales y no se encuentra una interpretación adecuada. Más aún, cuando nunca he encontrado representaciones de extremidades de animales en las esculturas americanas como para considerar que estos surcos representan falanges, como lo hacen en las figuras antropomórficas (generalmente de los dedos de la mano pero en ocasiones del pie; entre las que en este trabajo se encuentran ilustraciones por ejemplo de las figuras $\mathrm{N}^{\circ} 22,23$, 24, 25, 26, 258, láminas IX a XI).

Si se da vuelta a la figura de manera en que el pico apunte hacia abajo, se podría interpretar que los surcos representan los dedos de las patas delanteras dispuestas una sobre otra mientras que las patas traseras estarían hacia atrás. Esto significaría que la figura se trata de la representación de un animal cuadrúpedo. Bajo esta suposición y basándose en el aspecto de la cabeza, se piensa entonces en un reptil. Sin embargo, podría tratarse de un mamífero con trompa y con un engrosamiento en la frente por ejemplo una foca (del género Stemmatopus). Me parece que hasta este momento, ninguna de las posibilidades expuestas es la correcta, esto debido a que yo estuve activo en el ámbito zoológico en donde he discutido el tema con varios camaradas especialistas. Sí me fue posible establecer el significado de las figuras de los ídolos de tres cabezas como el que se encuentra ilustrado en la obra "Trabajos en nefrita" [Nephritwerk] (pág 34, Fig. 41 a, b, c, d), la identificación de las dos figuras de los extremos fue posible debido a que, sin ninguna duda, la figura central representa un ave.

En la figura 230, lámina VII del presente escrito, se encuentra la aclaración del significado del hocico de cuatro puntas que en este caso representa el hocico de un cachalote (Physeter).

Yo quiero todavía discutir, que se podría estar dispuesto a considerar cuál es el papel que juegan estas representaciones de animales en las llamadas "piedras calendario" mexicanas en las que las imágenes representan determinados días $(\mathrm{Ph}$. Valentini [Profesor en Nueva York] conferencia acerca de las "piedras calendario" mexicanas, Nueva York 1878, 80. con 1 lámina; Marrer e hijo). Se trata acerca de los siguientes reptiles lagartija
("Quetzpalin" mexicano), serpiente ("Cohuatl"); las siguientes aves: águila ("Quauhtli”), buitre y los siguientes mamíferos: conejo ("Tochtli"), ciervo ("Mazzatl"), perro ("Itzcuintl"i), tigre ("Tecuan") y simio (“Azomatl”).

De estos posiblemente se encuentran en la lámina VII, $\mathrm{N}^{\circ}$. 167: el conejo, $\mathrm{N}^{\circ} 250$ el perro, $\mathrm{y}$ posiblemente en el $\mathrm{N}^{\circ} 265$ la serpiente. Mientras que no es posible hacer una aserción correcta acerca de los animales que no están representadas en las "piedras calendario" (a excepción de las ya discutidas figuras $\mathrm{N}^{\circ} 173$ y 230) se encuentran las $\mathrm{N}^{\circ} 224,184,267$ y 263 . En cambio, sí se podría especular el significado de las siguientes figuras como en la $\mathrm{N}^{\circ} 62$ lámina IX una cabeza de búho, en la $\mathrm{N}^{\circ} 63$ una cabeza de pollo, y en la $\mathrm{N}^{\circ} 200$ lámina VIII una cabeza de un ave de pico largo. De esta última se puede determinar que la forma del objeto original tuvo una mayor influencia en la forma final con respecto a las otras, debido a que en la pequeña pieza de piedra no se observan señas de trabajo como rayas de cortadura.

Por lo demás, se debe acentuar el hecho de que en Costa Rica vivían los Chorotega cuyo lenguaje era distinto del de los pueblos mexicanos (ver "Etnografía general" de Mueller. Viena, segunda edición 1879, pág. 269). Por lo tanto, se debe tener en cuenta que en estos lugares se honraba otros animales que tenían un papel a manera de culto. Además, se debe pensar en la tribu de los cuevas, entre otros (ver "Trabajos en nefrita" págs. 404 y 257).

Con relación a las figuras antropomórficas, se trata en nuestro caso de las $\mathrm{N}^{\circ} 185,189,258,22$, $23,24,25,26$. En la $\mathrm{N}^{\circ} 185$ se reconoce el intento muy primitivo de representar a un ser humano, pero que sin lugar a duda la forma es reconocible al observar las líneas faciales, los ojos y el límite entre la parte inferior y superior del cuerpo. En la $\mathrm{N}^{\circ} 189$, lámina IX, es posible observar los brazos juntos, dispuestos horizontalmente. En la $\mathrm{N}^{\mathrm{o}} 25$, lámina XI observamos una banda en la frente con líneas organizadas extrañamente. Las $\mathrm{N}^{\circ} 22$ y 23 , lámina $\mathrm{X}$ se encuentran aproximadamente al mismo nivel, pero se diferencian en el caso de la $\mathrm{N}^{\circ}$ 22 por las gruesas franjas bajo el labio inferior $\mathrm{y}$ en la $\mathrm{N}^{\circ} 23$ por la posición distinta de los brazos que aparentan estar cruzados uno sobre otro. $\mathrm{La}$ $\mathrm{N}^{\mathrm{o}} 24$, lámina XI muestra la ornamentación más 
rica y la $\mathrm{N}^{0} 26$, lámina IX se caracteriza por la separación entre los brazos y el tronco y la diferenciación de las piernas.

En lo que respecta a la organización de esta interesante colección de esculturas costarricenses, se puede hacer basándose en los sitios en donde han sido encontradas. De aquí en adelante se les asignará las características correspondientes a los antiguos pobladores de las cercanías particulares. Sin embargo, acerca de esto se sabe muy poco y puede ser que influyan también casos en los que por coincidencia ocurra la deportación de un objeto desde un área a otra. Otra posibilidad es ordenar las piezas de acuerdo con su constitución mineralógica, pero en lo que a esto respecta, cabe la posibilidad de que el transporte natural lejos del área de origen de las rocas mediante ríos o arroyos no permita obtener un resultado significativo. Por lo tanto, he elegido el criterio de clasificación más objetivo, el cual es la naturaleza del trabajo artístico que presentan las piezas. Entonces ordeno las piezas de una manera en que a un trabajo tosco o una empuñadura que haya servido como herramienta (aunque hayan podido pertenecer también al culto) le antepongo una (A). Los objetos que simplemente servían de cuentas de collar para adorno se clasifican con una (B). Se numeran con un 2 aquellos objetos que se considera que colgaban mediante una perforación. De la misma manera, la representación de un animal o una figura antropomórfica que representan un nivel mayor de significado, esto último aparenta ser desconocido.

Para cada uno de los objetos que he examinado, con el sentido de llegar al diagnóstico mineralógico más acertado, se debió determinar otras características necesarias además del peso específico, por ejemplo, el color, cuya determinación es posible realizar de manera muy exacta desde la aparición de la "Escala Internacional de Colores"6 de Radde. Además, aunque a veces de manera aproximada, se determinó el significado y la forma. Las ilustraciones dadas sirven para la determinación de estos últimos aspectos y son referidas mediante un número, el cual es el correspondiente al número asignado para la pieza en el museo de Bremen. A nuestro parecer, es de esta manera como es más fácil de buscarlas en la lámina debido a que se trata de números consecutivos y debería presentar la mayor comodidad para aquellos lectores que estén en posición de compararlas con la figura original.

Entonces empezamos con la categoría A: Herramientas y similares.

\section{A. Herramientas (y similares)}

$\mathrm{N}^{\circ} 125^{7}$, lámina VII y 126: 70-90 mm de largo, peso específico 2,83 para la $125 ; 2,82$ para la 126. Aparenta ser trabajada a partir de dolerita y utilizada como piedra para machacar granos de maíz. Los canales profundos y paralelos entre sí están todos equidistantes en la 125. En la 126, existen 19 canales y el cuarto, sétimo décimo, decimotercero (o sea cada tres canales) son más gruesos y profundos. También en la 126 se agregó un canal en toda la periferia del panel lateral mediante el cual era más fácil sostener la herramienta. La superficie gruesa, café y manchada de amarillo (especialmente al humedecerla y verla con la lupa) de ambos objetos presenta brillo mate. $\mathrm{La}$ elección de un tipo pesado de roca apoya el significado de la pieza.

$\mathrm{N}^{\circ} 138$, cuerpo plano de forma linguoide de $9 \mathrm{~cm}$ de largo y de 1 a $1 \frac{1 / 2}{\mathrm{~cm}}$ de grosor. Posible instrumento para raspar. Fonolita? Peso específico: 2,46, algo plano-convexa, color gris-naranja (Radde $34, \mathrm{p}-\mathrm{q}$ ), su superficie húmeda deja ver bajo la lupa escasos cristales blancos y muchos puntos oscuros blandos al perforar con una aguja, posiblemente hidróxidos de hierro producto de la meteorización de minerales como magnetita o pirita.

$\mathrm{N}^{\circ} 259$, Piedra para afilar. Peso específico 1,95 ; longitud $10 \mathrm{~mm}$, tal vez arcillolita silicificada [Wetzschiefer]. Los bordes están desafilados, por lo tanto no se trata de un cuchillo. En uno de los lados se reconoce una superficie de rodado y un indicio de aserrado. Contra el borde desafilado hay una perforación vertical cónica (de un lado ancha, del otro angosta), esta era utilizada, como usualmente aquí encontramos, para colgar. El color es verde-azul (Radde entre 16, p-q y 17, p-q), la roca está cortada por vetillas de cuarzo y bajo la lupa muestra pequeñas y finas manchas blancas.

$\mathrm{N}^{\circ}$ 261, lámina VII. Punzón?; cuarzo?; peso específico 2,64, emite débilmente chispas con el acero, longitud de $10 \mathrm{~cm}$, presenta cuatro lados de los cuales el lado estrecho presenta señales de 
aserrado en ambos bordes, el lado contrario a este se encuentra arqueado; el color es amarillo-azulado sucio, manchado; no puede ser fundido ni exfoliado.

$\mathrm{N}^{\circ} 260$, lámina VII. Herramienta delgada similar a un cincel, con el lado angosto cortado con sierra, pulido liso. Compuesta por cuarzo, peso específico 2,61, color amarillo oscuro (Radde 7 d), en el borde cortante inclinado es brillante. En la base estrecha tiene una perforación vertical.

N 190, lámina VII. Herramienta corta similar a un cincel con la base perforada verticalmente; se reconoce la superficie de un rodado. Compuesta por cuarzo, peso específico 2,61; color gris-verdoso (Radde $36 \mathrm{n}$ ) con manchas claras grandes causadas por planos internos de fractura.

$\mathrm{N}^{\circ} 114$, lámina VII. Hacha corta, compacta, fuertemente biconvexa con cortes empinados, color gris-naranja (Radde 34 q); peso específico 2,94. Emite chispas débilmente con el acero; una diminuta esquirla de la sustancia fue infundible con el soplete y no se tornó azul ante la solución de cobalto; el diagnóstico de este material debió ser dejado abierto, de lo contrario habría que cortar un gran pedazo de la pieza. Sin embargo, se puede determinar a partir del alto peso específico, que no se trata de cuarzo, sino de una sustancia hasta ahora desconocida; se puede entonces de la manera más honesta, tratar como bamlita (variedad de silimanita) que hasta ahora solo se conoce en Noruega y externamente se parece a la silimanita (fibrolita: silimanita fibrosa). No se puede tratar de fibrolita, que ha sido frecuentemente encontrada a manera de hachas en Europa y China, debido al que la fibrolita presenta un peso específico de 3,2 - 3,4 mientras que el hacha $\mathrm{N}^{\circ} 114$ presenta solo 2,94 . Este ejemplo muestra la importancia de la determinación del peso específico debido a que es posible dejarse inducir hacia un diagnóstico erróneo como el cuarzo, debido al color, dureza, e infusibilidad.

$\mathrm{N}^{\circ} 257$, lámina VII. Herramienta plano convexa con anillos, alrededor de los lados, uno de los cuales al extremo se encuentra perforado verticalmente, con el canal de perforación cónico; los agujeros para cuerda son irregularmente espaciados. El lado superior es convexo, el lado inferior es plano con un sitio de fractura largo y elíptico como resto del trabajo de aserrado; peso específico de 3,21; jadeíta? en toda la masa está pobremente pulido, verde-azul (Radde 16 l-o). Manchas blancas ebullen del lado afilado a través del cual se observan planos de fractura internos.

$\mathrm{N}^{\circ} 113$, lámina VII. Instrumento grueso, irregular, de forma linguoide, arqueado en los planos, los bordes son casi tan afilados como cuchillo; la superficie se encuentra lisa, pulida como un espejo; el borde estrecho está perforado verticalmente con una perforación cónica. Muestra en parte una superficie de un rodado, emite chispas ante el acero. Peso específico 3,30. Jadeíta verde-azul (Radde 16 n-o) con manchas pálidas translúcidas de $16 \mathrm{r}$ a través de los cantos.

$\mathrm{N}^{\circ}$ 112, lámina VII. Herramienta larga, estrecha lis y pulida, similar a un cuchillo. Aproximadamente $150 \mathrm{~mm}$ de largo, $40 \mathrm{~mm}$ de ancho, con extremos inclinados no redondeados de los cuales uno es más convexo. Peso específico 3,33. Jadeíta verde-azul (Radde 17 f) translúcida azul con franjas blancas, no está perforada.

№ 111, lámina VII. Herramienta plana, similar a un hacha, con un lado más plano, hacia el lado estrecho se encuentra perforada verticalmente de forma cónica. El agujero para cuerda está más hacia el lado convexo. Peso específico 3,32. Jadeíta verde-azul (Radde 16 f-o) pulida muy lisa, prácticamente translúcida color azul; solo hacia la parte más externa del lado cortante el color es muy claro, por cierto con manchas como franjas verde-claro. Es debido al color, el objeto más bello de toda la colección (comparar con la parte superior).

Es posible notar que estos últimos bellos objetos, pueden ser considerados también como ornamentos.

\section{B. Ornamentos}

\section{Sin representaciones de animales o personas}

Con perforaciones longitudinales, con forma aproximada de cilindro, esfera, u óvalo ( $\mathrm{N}^{\circ}$ 177-202).

$\mathrm{N}^{\circ} 177$. Cuenta en forma de esfera compuesta por arcilla color verde claro (peso específico 2,01), perforada longitudinalmente, lado inferior plano.

$\mathrm{N}^{\circ}$ 193. Cuenta perforada longitudinalmente, del tamaño de un guisante, compuesto por calcedonia grisácea que cambia a amarillo, peso específico 2,50. 
$\mathrm{N}^{\circ}$ 178: Cuenta en forma de esfera, perforada longitudinalmente compuesta por gabro con diálaga verde (?), peso específico 2,78 ; gris verdoso (Radde 37, o-r); dureza 6; mezcla de partes verdes e incoloras.

$\mathrm{N}^{\circ}$ 181. Cilindro redondeado, corto de aproximadamente $1 \mathrm{~cm}$ de largo, perforado longitudinalmente con canal de la perforación cónico a ambos lados; peso específico 4,78; compuesto por pirita, mate en toda la superficie, color café, recubierta de limonita. También en este caso solo la determinación del peso específico puede llevar al diagnóstico correcto debido a que el color café de la limonita en el exterior puede llevar a pensar en que toda la pieza se compone de esta.

$\mathrm{N}^{\circ} 182$, lámina VIII. Cilindro fracturado en tres partes, en los planos de fractura se observa el color amarillo y el brillo metálico de la pirita; también es posible observar cómo el agujero de la perforación se estrecha hacia el centro. (En el mismo cartón se encuentran pegados otros pedazos de pirita y un pequeño fragmento de cristal de roca).

$\mathrm{N}^{\circ}$ 192. Cuenta cilíndrica, casi de forma ovalada, perforada longitudinalmente, compuesta por arcilla, peso específico 2,01 .

$\mathrm{N}^{\circ}$ 170: óvalo delgado, corta de $2,33 \mathrm{~cm}$ de largo compuesta por ópalo (?), peso específico 1,97, color azul-verdoso oscuro (Radde $16 \mathrm{c}$ ). El color puede indicar heliotropo, sin embargo el peso específico tan bajo indica lo contrario; dureza 5-6.

$\mathrm{N}^{\circ} 169$, lámina VIII. Óvalo delgado de 3,33 $\mathrm{cm}$ de longitud, perforación longitudinal con el canal ligeramente cónico, cuya superficie presenta pequeños hundimientos; compuesta por ópalo (?), peso específico 2,03; verde-azul oscuro (Radde 16 c) con manchas alargadas color verde claro.

$\mathrm{N}^{\circ} 168$, lámina VIII. Óvalo grande de $6 \mathrm{~cm}$ de longitud, diámetro máximo de $9 \mathrm{~cm}$, pulida lisa, perforación longitudinal con el canal interno torcido y estrecho. Peso específico 5,52, cuarzo, variedad heliotropo verde azulado oscuro (Radde $17 \mathrm{f}-\mathrm{g}$ ) con manchas claras compuestas por intercrecimientos de una sustancia suave dentro de la masa principal; en donde esta partícula se ha desmoronado no muestra cavidades.

$\mathrm{N}^{\circ} 60$ y 61, lámina VIII. La primera con un peso específico de 2,62 y la segunda 2,60; se ven como bandas de servilleta con un canal algo estrecho, pulidas, mate y ambas se componen del mismo material que destella al acero, posiblemente cuarzo variedad calcedonia, o cornubianita algo translúcida, color gris-verdoso (Radde 37 1n); ambas piezas poseen una mancha amarilla en un determinado lugar a un lado como si en algún momento ambas hubiesen formado parte de una cadena, como eslabones una al lado de la otra. El objetivo de estas piezas no lo puedo explicar, tal vez pudo haber sido el sostén de un penacho.

Los siguientes objetos parecen ser trabajados a partir de una sustancia similar a la $\mathrm{N}^{\circ} 168$ aunque con un color un poco más de verde y menos hacia el azul.

$\mathrm{N}^{\circ} 264$. Óvalo pequeño de $3 \mathrm{~cm}$ de largo, en parte aplanada, el canal de la perforación es recto y de diámetro uniforme, color verde-azul (Radde $16 \mathrm{f}-\mathrm{g}$ ), cuarzo variedad heliotropo, peso específico 2,47 .

N 174, lámina VIII: Cilindro achatado mediante presión, fracturado en uno de sus extremos con dos caras anchas y dos caras estrechas. Peso específico 2,54; cuarzo variedad heliotropo, color verde-pasto oscuro (Radde 15 e-f).

$\mathrm{N}^{\circ} 27$, lámina VII. Tubo largo de $23 \mathrm{~cm}$ de longitud, $2 \mathrm{~cm}$ de diámetro; con perforación longitudinal con ambos extremos cónicos, en la parte interior es muy estrecho y torcido. En un caso se observa la superficie de rodado; color gris verdoso-amarillo (Radde 36 r) con manchas amarillentas y verde oscuro; peso específico 2,91; destella levemente al acero, la textura cristalina es reconocible. No se pudo obtener una esquirla lo suficientemente grande como para el estudio en el microscopio, pese a ello la apariencia exterior y la longitud del objeto son un poderoso indicio de la procedencia de la roca, como un esquisto micáceo al igual que las $\mathrm{N}^{\circ} 22,23$, y 24 .

A continuación se presentan objetos muy distintamente estructurados, más pequeños, con perforaciones longitudinales o en otra dirección, para colgar como ornamentos o amuletos. Estos aparentan indicios de representar, en parte, formas de animales.

$\mathrm{N}^{\circ}$ 180, lámina VIII; Cilindro con redondez irregular y cuatro constricciones, $3,5 \mathrm{~cm}$ de largo, pulido mate, con canal de perforación aparentemente regular; dureza 4, peso específico 2,76, 
compuesto por (gabro)-serpentina?, gris verdoso (Radde 37 o-r). Se puede observar claramente a través del pulido y al igual que en las figuras $\mathrm{N}^{\circ}$ 178 y 179, la fábrica hojosa y la disposición cruzada de las pequeñas hojas verdosas (diálaga?), especialmente al humedecer la superficie.

$\mathrm{N}^{\mathrm{o}} 202$, lámina VIII. Ornamento de forma cilíndrica corta y gruesa, con fuertes constricciones en ambos extremos y perforación longitudinal. La superficie externa es completamente mate, no trabajada, agrietada; color gris-verdoso (Radde 37 q-r). Peso específico 2,57. Feldespato? variedad sanidina?

$\mathrm{N}^{\circ} 179$, lámina VIII. Cuerpo plano con cuatro apófisis con ángulos rectos en las esquinas y una prominencia con cuatro esquinas en el centro. Esta prominencia está perforada verticalmente, así que toda la figura asemeja el herraje de una puerta con el agujero para la llave; en la parte posterior se nota un hundimiento plano, redondo, con una incisión que asemeja también una cerradura con llave; dureza 4-5, peso específico 2,90; (gabro-) serpentina, gris-verdoso (Radde 37, o-r), en parte con pequeñas manchas verdes bien definidas.

$\mathrm{N}^{\mathrm{o}} 184$, lámina IX. Ornamento pequeño, plano, con cierta forma de oreja. Perforado verticalmente en el extremo grueso. Peso específico 2,86; serpentina? amarillenta.

$\mathrm{N}^{\mathrm{o}} 188$, lámina VIII. Ornamento plano, pulido, perforado verticalmente en el lado largo; peso específico 2,95; en un extremo quebrado se observa textura hojosa a partir de la cual junto con el color pasto verde-oscuro, se puede concluir que se trata de un mineral del tipo Strahlstein.

$\mathrm{N}^{\circ} 267$, lámina VIII: ornamento plano con un apófisis semicircular a un lado, perforada verticalmente, y al otro lado se encuentra quebrado de manera oblicua. Inicialmente pudo haber representado la cabeza de un animal, peso específico 2,61; cuarzo color pasto verde oscuro (Radde 15, d); sitios color verde claro manifiestan la exfoliación a través de las superficies pulidas.

$\mathrm{N}^{\circ}$ 198: este ornamento se asemeja a una cabeza plana de animal con apófisis laterales, siendo posible que en su totalidad la forma represente un mero fenómeno de la naturaleza; peso específico 2,17; dureza 6 , compuesto por ópalo común (?) gris-verdoso (Radde 37 r-s) en su interior es más verde-azul (Radde 16 o).
$\mathrm{N}^{\circ} 171$, lámina VIII. Figura dudosa, peso específico 2,24; compuesta por ópalo común, verde-azul oscuro (Radde 16 e).

\section{Figuras de animales}

N 175, lámina VIII. Cabeza de ave (?), peso específico 2,27; ópalo común (?), verde-azul oscuro (Radde 16 e).

N²65, lámina VIII. Cabeza de serpiente (?), peso específico 2,20; ópalo común (?), verde-azul oscuro (Radde 16 e).

$\mathrm{N}^{\circ}$ 263, lámina IX. Representación dudosa de animal; sustancia igual a la del $\mathrm{N}^{\circ} 202$; peso específico 2,52; sanidina (?).

$\mathrm{N}^{\circ} 200$, lámina VIII. Cabeza de ave (?) posiblemente fenómeno o creación figurada, peso específico 2,72; superficie en bruto, gris, con manchas negras, andesita con anfíboles (?); en todo caso, una roca mezclada.

$\mathrm{N}^{\circ} 250$, lámina VIII. Cabeza de perro (?), peso específico 2,75; muscovita cromífera con dos ejes ópticos (?), verde pasto, la superficie permite observar la fábrica hojosa.

$\mathrm{N}^{\circ} 230$, lámina VIII. Cachalote (?), peso específico 3,32 ; jadeíta (?), (ver anterior) blancuzca (Radde $17 \mathrm{t}$ ).

$\mathrm{N}^{\circ}$ 62, lámina IX. Cabeza de águila (?), peso específico 2,76; cuarzo, blancuzco (gris-verdoso amarillento, Radde $36 \mathrm{~s}$ ).

$\mathrm{N}^{\circ} 63$, lámina IX. Cabeza de gallina (?), peso específico 2,65; cuarzo, blanco amarillento (Radde $36 \mathrm{v}$ ).

$\mathrm{N}^{\circ} 302$, lámina VIII. Pez (?) (ver anterior), peso específico 2,57; cuarzo, variedad calcedonia, verde pasto (Radde $15 \mathrm{f}$ ) con trazas amarillentas en forma de oveja o nube. Los surcos laterales paralelos podrían indicar las aletas.

$\mathrm{N}^{\circ}$ 167, lámina VIII. Cabeza de cálao(?), conejo(?) (ver anterior); peso específico 2,56; cuarzo, variedad calcedonia, marrón (gris-amarillento similar al cinabrio, Radde $1 \mathrm{f}$ ) y verdeazul (Radde 16 p); en toda su masa es algo translúcido.

$\mathrm{N}^{\circ}$ 173, lámina VII. Animal dudoso, peso específico 2,57; calcedonia similar a la $\mathrm{N}^{\circ} 167$, marrón (Radde 33 g) y verde-azul (Radde 16 p), finamente moteado color blanco.

Finalmente llegamos a la tercera categoría: 


\section{Figuras de personas}

Están formadas de la manera más primitiva y apenas reconocible.

$\mathrm{N}^{\circ} 185$, lámina IX. Peso específico 2,54; fonolita (?) color gris verdoso claro (Radde 37 q) con manchas amarillo-herrumbre; a cada lado hay una perforación vertical aproximadamente al nivel de los ojos; presenta una alusión primitiva a una banda en la frente; se pueden apreciar los párpados y líneas transversales que muestran el límite entre abdomen y tórax.

$\mathrm{N}^{\circ} 189$, lámina IX. Figura rudimentaria con la cabeza inclinada, banda de frente, ojos, comisuras de la boca, brazos arqueados horizontales y manos chocando una con otra; peso específico 3,00; verde-pasto (Radde 15 o), prenhita (?), rayada un poco por el cuarzo. Bajo la superficie del pulido es discernible la textura cristalina fibrosa.

$\mathrm{N}^{\circ}$ 262, lámina IX: figura estrecha, formada de manera poco clara. Carece de ojos y cara, solo posee una banda en la frente; perforación horizontal al lado, color verde-pasto (Radde $15 \mathrm{~d}$ ), en la superficie cortante muestra manchas negras de la exfoliación; peso específico 2,27; nontronita (??).

$\mathrm{N}^{\circ} 25$, lámina XI. Jadeíta (?) con peso específico 3,34; destella, $218 \mathrm{~mm}$ de largo, $58 \mathrm{~mm}$ de grosor máximo, color verde-azul (Radde 16 q-r). El lado de atrás está muy fuertemente torcido, la cara está representada muy primitivamente. Son muy interesantes unas líneas similares a meandros presentes en la banda de la frente, estas se diferencian de la esvástica de la India (ver: Schliemann Ilios, 1881, según Max Müller); los brazos están dispuestos horizontalmente uno a otro; tiene manchas más claras y rayas amarillas $-217 \mathrm{~mm}$ de largo, $55 \mathrm{~mm}$ de grosor.

$\mathrm{N}^{\circ} 258$, lámina IX. Jadeíta (?) peso específico 3,31; figura antropomórfica estrecha con el borde de la cabeza dentado, bandas en la frente, párpados grandes arqueados, brazos delgados, las manos yacen una sobre otra encima del abdomen; no se distinguen piernas. Pulida como un espejo, la parte de atrás muestra líneas de aserrado, presenta perforaciones vertical, horizontal y submarginal, verde-azul grisáceo (Radde 38, máximo 38 s, podría ser también $38 \mathrm{~m}$, la parte de atrás es más oscura hasta $38 \mathrm{k}$ ); $134 \mathrm{~mm}$ de largo y $28 \mathrm{~mm}$ de grosor máximo.
$\mathrm{N}^{\circ} 23$, lámina $\mathrm{X}$. Esquisto micáceo (?), peso específico 2,69; destella un poco ante el acero. El color de la roca es mezclado entre anaranjado (Radde $5 \mathrm{t}$ ) y manchas verdes (Radde $15 \mathrm{q}$ ), a partir de la orilla de atrás es café (cercano a Radde 33p).

El hecho de que el Sr. Director Ludwig no haya podido otorgarme el permiso de cortar un pedazo de estas costosas antigüedades $\left(\mathrm{N}^{\circ} 22\right.$, $23,24,27)$ lo suficientemente grande como para hacer una sección delgada, ha evitado que yo determine la composición de pequeños puntos y ha limitado mi análisis del tipo de roca a las características observadas en la muestra de mano. Sin embargo sí me ha otorgado el permiso de llevar a cabo pruebas básicas de la manera más liberal, especialmente en caso de que macroscópicamente un material aparenta ser un mineral determinado y se ubique en el ámbito de los silicatos, es cuando entra en consideración su peso específico ${ }^{8}$.

Finalmente llevé a cabo los estudios comparativos con las piedras de collar mexicanas pertenecientes a nuestro museo que presenten una composición similar y a partir de las cuales yo he podido realizar secciones delgadas de tamaño suficiente, para una mejor comprensión de las más pequeñas y finalmente para realizar el diagnóstico. A partir del diagnóstico se observa que el esquisto micáceo se encuentra en la naturaleza a una escala tan significativa que permitió la confección de figuras tan grandes como las anteriormente mencionadas. A este diagnóstico aporta también el hecho de que el material destella ante el acero lo cual indica la presencia de cuarzo, el cual se encuentra generalmente en el esquisto micáceo. Aparentemente varias partículas prismáticas o con arreglos en esquinas y que en sección delgada se observan entre las hojas de las micas, se pueden asociar en ciertas piezas con cristales aciculares de hornblenda(?) verdosa.

En lo que respecta a la escultura como tal, se observa la presencia de bandas en la frente con líneas en ángulos agudos como es frecuente encontrar en Centroamérica y que no se encuentra en ningún otro lado, a lo que también se debe poner atención a que aquí no se presentan los brazos colocados a los lados del abdomen con las manos de ambos lados colocadas una sobre otra en la línea media del cuerpo reconocidas simplemente a partir de líneas horizontales que corresponden 
con los dedos. Más que todo, se observa que los brazos se colocan horizontalmente sobre el abdomen, uno sobre otro de manera en que la mano derecha yace sobre el lado izquierdo y la izquierda sobre el lado derecho. Esto se hace de manera en que el propósito de la colocación de las manos sea representar una honorable reverencia de todo el cuerpo de parte de las gentes concientes. La parte posterior de esta escultura está fuertemente torci$\mathrm{da}-237 \mathrm{~mm}$ de largo, $71 \mathrm{~mm}$ de ancho.

$\mathrm{N}^{\mathrm{o}}$ 24, lámina XI. Esquisto micáceo(?), peso específico 2,92; dureza alrededor de 7, color anaranjado sucio (Radde $4 \mathrm{~s}$ ) con manchas oscuras (Radde $5 \mathrm{i}), 230 \mathrm{~mm}$ de longitud, $75 \mathrm{~mm}$ de grosor.

Con respecto a la escultura $\mathrm{N}^{\circ} 24$, es la escultura que presenta la decoración más rica de toda la colección. A partir de las bandas horizontales de la frente que presentan trazas angulosas, se eleva un tipo de turbante alto adornado con algunas franjas perpendiculares y angulosas y del cual, un sitio a uno de sus lados se hunde y bajo este se aprecia una apertura lateral para la cuerda que se presenta a ambos lados a manera de un canal no horizontal. En las comisuras de la boca se presentan a ambos lados, 4 hundimientos perpendiculares redondeados que se encuentran uno sobre otro, estos son un poco más pequeños que los ojos, en la zona maxilar se representan los dientes (?) mediante líneas perpendiculares. En el labio inferior se representa una placa grande, rectangular (indica una "piedra de labio", llamada "Tentl" en México?), en ángulo recto a esta, hay otro rectángulo enmarcado a partir del cual sale hacia abajo una figura angulosa, mientras que a la derecha e izquierda se encuentran grabadas líneas dobles inclinadas y también en la parte media, 5 líneas horizontales correspondientes con los dedos. En esta escultura se observa en la parte posterior plana, el sitio de la unión y el lugar del aserrado, al igual que en las figuras 22,23 , y 25 . Aunque muy poco inclinado, se observa en el extremo anterior, el sentido inclinado del aserrado en el recodo de la unión.

$\mathrm{N}^{\circ}$ 22, lámina X. Esquisto micáceo(?), igual que $\mathrm{N}^{\circ}$ 23; peso específico 2,73; gris-verdoso (Radde 37 s), parte posterior inclinada. En esta figura hay una banda de frente con trazas angulosas abiertas hacia la izquierda, cavidades oculares, a ambos lados en las comisuras de la boca hay un hundimiento redondo y hacia arriba de la boca hay una placa grande con cuatro esquinas (Placa labial?, "Tentl") que a ambos lados tiene estrías inclinadas. Las manos se encuentran sobre el abdomen, una sobre otra de manera horizontal - longitud de $260 \mathrm{~mm}$ y $70 \mathrm{~mm}$ de grosor máximo.

$\mathrm{N}^{\mathrm{o}} 26$, lámina X. Jadeíta (?), peso específico 3,29; color gris-verdoso (Radde $37 \mathrm{n}$-p) la parte posterior es un poco más oscura. Figura antropomórfica con decoración peculiar en la cual en el medio aparenta destacar un lóbulo hacia el frente, la nariz es muy gruesa, el maxilar es prominente, las manos se encuentran en medio del abdomen una sobre otra. Lo interesante de esta figura es la separación de los brazos del torso y la diferenciación de las piernas, lo cual no se observa en ninguna otra figura de piedra de esta área. En las figuras mexicanas de arcilla, por ejemplo en los cientos de figuras que están en el museo de Basilea, se observa una completa separación de los brazos y el torso. La elaboración de tales figuras obviamente debió haber sido la etapa de modelo para las figuras de piedra. $141 \mathrm{~mm}$ de longitud, $45 \mathrm{~mm}$ de grosor.

$\mathrm{N}^{\circ} 37$, lámina IX. Jadeíta (?), peso específico 3,30; dureza 7-8, color blanco (azulado claro Radde 19 u), cabeza humana en la que se distingue la banda de la frente solo por dos líneas horizontales, las cavidades oculares están oblicuas, se reconocen los párpados, la boca, y la nariz. La escultura está pulida tan lisa como un espejo y esto permite que brille desde adentro la textura cristalina fibrosa.

$\mathrm{N}^{\mathrm{o}} 40$, lámina IX. Jadeíta (?), peso específico 3,30; dureza 7-8, al igual que la $\mathrm{N}^{\circ} 37$ esta no presenta franjas de cuarzo. Color blancuzco (gris verde-azulado Radde 38 q-r). Cabeza humana, la banda de la frente tiene rayas perpendiculares, se reconocen los ojos, fístulas oculares, líneas de la boca, la nariz está arqueada. $\mathrm{La}$ escultura está pulida tan lisa como un espejo y al igual que en la $\mathrm{N}^{\circ} 37$ el interior brilla debido a la textura cristalina .

En relación con el mineral jadeíta, a partir del cual aparenta que se trabajaron las figuras $257,110,111,112,113,230,25,258,26,37$ y 40 , tengo que enfatizar a partir de una vista general, que los objetos similares a herramientas se componen de la variedad verdosa-azulada 
translúcida, las figuras antropomórficas y también las representaciones de animales $\left(\mathrm{N}^{\circ} 230\right)$ se componen de las variedades más grisáceas o blancuzcas. En esta colección no se encuentra la bella variedad verde-esmeralda de la jadeíta como la que yo conozco en las piedras de collar de México y que se encuentra a manera de un color idéntico en la materia prima procedente de Indochina, obtenida a través de China mediante el Cónsul Imperial Alemán Barón von Soden en Hong Kong.

\section{PROCEDENCIA DE LOS OBJETOS DE ESTA COLECCIÓN}

El lugar en que se encontró cada uno de estos objetos fue provisto por parte del coleccionista Sr. Cónsul Lahmann (ver anotaciones anteriores). Mediante una vista general es posible ver cómo se reparten los hallazgos en distintos pueblos, siendo las provincias aquí indicadas, junto con los grados de latitud y longitud (a partir de Greenwich) además se indica de manera mineralógica, el material.

1. Santa Cruz ( $10^{\circ} 2^{\prime}$ 'Lat. N., $85^{\circ} 6^{\prime}$ Long. W.) provincia de Liberia.

$\mathrm{N}^{\mathrm{o}} 110,111,112,257,258$ jadeíta(?); 114 esquisto micáceo (?); 260, 261, 264, 267, 273 cuarzo; 175, 265 ópalo(?); 262 nontronita (?); 125 , 126 dolerita(?); 263 sanidina(?); 259 arcillolita silicificada(?).

2. San Ramón (10²' Lat. N., 84 6' Long. W.) provincia de Alajuela.

$\mathrm{N}^{\mathrm{o}} 178$ gabro con diálaga(?); 180, 179 (gabro-) serpentina(?); 177 arcilla; 181, 182 pirita.

3. Palmares $\left(10^{\circ} 1^{\prime}\right.$ 'Lat. N., $84^{\circ} 5^{\prime}$ Long. W.) provincia de Alajuela.

$\mathrm{N}^{\circ}$ 25, 26, 37, 40 jadeíta; 24, 27, 22, 23 esquisto micáceo; 173, 174 cuarzo; 200 andesita con anfíboles(?). Las número 22 a 27, 37 y 40 fueron encontradas en la misma tumba. Lo cual es interesante pues son las figuras antropomórficas y cabezas más grandes y bellas además de ser en parte las que se componen del material más costoso.

4. Santa Ana ( $10^{\circ} 1^{\prime}$ 'Lat. N., $84^{\circ} 5^{\prime}$ Long. W.) provincia de San José.

$\mathrm{N}^{\mathrm{o}}$ 60, 61, 62, 63, 167, 302 cuarzo; 169, 170, 171 ópalo (?); 111 jadeíta.
5. San Vicente $\left(9^{\circ} 11^{\prime}\right.$ Lat. N., $84^{\circ} 2^{\prime}$ Long. W.) provincia de San José.

$\mathrm{N}^{\circ} 250$ muscovita cromífera(?).

6. Agua Caliente y Tuis $\left(9^{\circ} 10^{\prime}\right.$ Lat. N., $83^{\circ}$

$11^{\prime}$ Long. W.) provincia de Cartago .

$\mathrm{N}^{\circ}$ 190, 193 cuarzo; 180 fuchsita(?); 189 muscovita(?); 188 strahlstein(?); 230 jadeíta(?); 202 sanidina(?); 192 arcilla; 183 (de Tuis) y 185 fonolita (?).

Mediante esta vista general, es posible darse cuenta que esculturas del mismo material han sido encontradas en distintos puntos. El haber encontrado tantos y tan bellos objetos en la misma tumba, indica que esta albergaba a un reconocido difunto, el cual era digno de otorgarle la posesión más preciada.

Para concluir quiero enfatizar lo importante que es el sentido de los estudios etnográficos, arqueológicos y prehistóricos mediante escritos unificados y también mediante el empleo de acceso a museos públicos con el fin de ampliar el conocimiento a los mayores círculos posibles. $\mathrm{La}$ adquisición de objetos como los descritos anteriormente y su traslado hacia Europa como el sitio central de la ciencia, va a llevar hacia adelante necesarios intereses de la población, los cuales dependen de circunstancias apropiadas, por último, las ciencias anteriormente mencionadas no serán aplicadas ni de manera mínima, por los representantes que se encuentran de paso, sino que lo hará gente de otras profesiones quienes estén en contacto de manera constante con las poblaciones en las áreas de interés, por ejemplo el caso de los médicos, pero también personas quienes tengan un puesto oficial por ejemplo cónsules y mercaderes. Estos pueden poseer conocimientos acerca de piezas generalmente dispersas en partes, en distintas familias, y generalmente no tomadas en cuenta, así como piezas encontradas en nuevas excavaciones; por ejemplo pueden facilitar y representar de manera correcta información sobre sitios, por ejemplo de tumbas.

Una gran cantidad, o mejor dicho, la mayoría de las esculturas provenientes de Centroamérica y México, las cuales también he tratado en publicaciones anteriores, llegan a Europa mediante las relaciones caracterizadas a continuación por ejemplo la bella colección de Uhde en Handschuchsheim 
en las cercanías de Heidelberg del Sr. Waldemar Schlieden, que luego fue vendida al Museo Real en Berlín. Así como la extraordinaria colección del Sr. Phil. J. Becker de Darmstadt, la de Lucas Vischer de Basilea (que llegó al museo a manera de donación), la colección del Sr. Dr. Bilimek, médico del emperador Max de México (ahora adquirida por el Museo Real Imperial de Viena), la del Sr. Hermann Strebel en Hamburgo, la del difunto Dr. A. v. Frantzius en Friburgo (ahora comprada por el Museo de Friburgo).

Solo en el caso de que el congreso americano realizara una exposición de antigüedades americanas similar a la realizada en 1881 en Berlín para objetos alemanes, se podrían proveer las colecciones anteriormente mencionadas provenientes de Alemania, Austria, y Suiza que aquí solo el Museo de Bremen presenta de manera digna al nivel de los museos reales en Copenhague y Leyden, los cuales las presentan no como piezas solamente de exhibición - a excepción de los objetos en el Museo de Berlín - sino como antigüedades valoradas científicamente como en las publicaciones citadas.

Estos tesoros arqueológicos ya estuvieron, durante un tiempo suficientemente largo, fragmentados en cada uno de los museos, sin haberles dado la validez que merecen ya sea por sí solos o por comparación con otros objetos similares.

No conozco grandes colecciones en Alemania o en los países fronterizos, a las que se les pueda someter a un proceso. Con excepción del resto de los objetos encontrados en el Museo de Copenhague a los cuales he obtenido acceso mediante pequeños y frecuentes envíos por la buena voluntad del Sr. Chambelán von Worsaae y que contienen valiosos hallazgos de las islas de las indias occidentales danesas (pero también de Japón, Java, etc.).

En el Museo de Antigüedades del Reino de los Países Bajos en Leyden, yacen unos hallazgos de piezas de jadeía de mucha importancia provenientes de Yucatán. Yo conocí estas piezas mediante moldes cortesía del director Sr. Dr. Leemans. Entre ellas se encuentran un hacha y una placa de cuatro esquinas con una bella figura grabada en uno de los lados y jeroglíficos mexicanos en el otro. Estos jeroglíficos, al igual que los encontrados en las llamadas Hachas de Humboldt (Fischer "Trabajos en nefrita" pág. 31, Fig. 36), por el momento están siendo descifrados por el Sr. Prof. Ph. Valentini en Nueva York.

Las esculturas americanas que se encuentran en el departamento mineralógico del Museo Británico en Londres las conozco en privado a partir de ilustraciones, contrario a esto no conozco el inventario de los departamentos etnográfico y arqueológico de este museo. Lo mismo aplica en el caso de los museos de Rusia, Francia y España. En este último país podría esperar encontrar bellas antigüedades de la conquista de México.

Hasta donde yo sé, se conoce muy poco acerca del trabajo de las pequeñas esculturas de América, entre otros en los escritos de E. G. Squier por ejemplo en "Observations on a Collection of Chalchihuites from Central America" Read April 5th, 1869, in Annals of the Lyceum of Natural History of New York 1869. Aquí -como se aprecia- solo se trabajó los objetos arqueológicamente sin ninguna referencia sobre la sustancia mineralógica por parte de especialistas ni a través del peso específico, la dureza, la composición química y sin ningún detalle acerca de si se trata de un mineral homogéneo o un tipo de roca criptocristalina.

Lo mismo aplica para la publicación en portugués de J. Barbosa Rodrigues en Río de Janeiro relacionada con pequeñas esculturas encontradas en la corriente del Amazonas. Mi recomendación sería la misma, la determinación del peso específico de estas antigüedades de piedra por parte de un especialista. A pesar de que no es posible hacer una autopsia, esta prueba permitiría determinar cuales de los objetos de piedra de la colección brasileña se componen de nefrita, jadeíta o cloromelanita. Minerales que ya conozco que existen en piezas en los museos de Berlín, Viena y Milán primero. En Berlín hay un amuleto de nefrita proveniente de Brasil y una cuña de nefrita de Venezuela, en Viena un hacha de cloromelanita de Atacama (Chile) y en Milán un hacha de jadeíta de las pampas de la República Argentina . Otro objeto que amerita el estudio mineralógico, petrográfico pero sobre todo arqueológico, son los ídolos centroamericanos y mexicanos, cuya mayoría están hechos a partir de rocas volcánicas. Estos objetos se encuentran en los museos de Basilea, Berlín, Bremen, Darmstadt (Becker) y debido a la falta de espacio y al más alto grado de negligencia, están empolvándose colocados 
en el piso o en las partes más altas de los estantes, mereciendo sin embargo tanta atención como las figuras egipcias trabajadas a partir de granito, sienita, etc.

\section{Notas}

${ }^{1}$ Nephrit und Jadeit, mineralogisch und ethnographisch u.s.w. (Nefrita y Jadeita, mineralógica y etnográfica etc.) Stuttg. 1875. 8. Schweizerbart, mit 131 Holzschnitten und 2 chromolith. Tafeln; 2. vermehrte Ausgabe 1880; ferner im Archiv f. Anthropologie v. Ecker und Lindernschmit: die Mineralogie als Hilfswissenschaft $f$. Arch. und Ethnogr. 1879. Bd. XII und XIII; über Amazonenstein, Bd. XII. 1879; über Timur's Grabmal Bd. XII; in den Mitteilungen d. anthrop. Ges.z. Wien, Bd. VIII. 1878. Mineralog. archaeol. Studien u.s.w.

${ }^{2}$ Las esculturas mencionadas anteriormente forman solo una pequeña parte de las más de 1000 piezas que contiene la colección de antigüedades costarricenses, las cuales fueron recolectadas en el transcurso de varios años por el Sr. Cónsul Joh. Friedr. Lahmann en San José. La colección entera fue comprada por una asociación de ciudadanos de Bremen por un precio de 10000 marcos alemanes a manera de contribución voluntaria, y fue donada de la manera más generosa a las colecciones estatales de historia natural y etnografía de Bremen en diciembre de 1879. Contiene principalmente instrumentos e ídolos de roca volcánica así como artículos de arcilla pintada. Estos objetos presentan también un habilidoso trabajo.

${ }^{3}$ También fue muy interesante encontrar un objeto que presenta el mismo aserrado en medio de un estrecho puente de fractura, entre los amuletos planos de nefrita que me fueron enviados provenientes de la más reciente expedición del $\mathrm{Sr}$. Dr. Emil Riebeck a Asia Menor.

${ }^{4}$ Ver mi ensayo: Über die mineralogische Bestimmung archäologischer Objekte (Acerca de la determinación mineralógica de objetos arqueológicos), im Neuen Jahrb. F. Mineralogie, Stuttg. 1880.

5 Ver: FISCHER, Nephrit und Jadeit (nefrita y jadeíta) pág. 231, 364 a 375, luego en Neuen Jahrb.f. Miner. 1880, Bd. 1. pág. 1 a 3. Corrsp.Art. über Jadeit aus Hinterindien (acerca de la jadeíta de Indochina); 1881. Bd. 1. Corrsp. Art pág. 171 - 178; ferner im Corrsp. Blatt d. deutsch. anthrop. Ges. 1879. N. 3 pág. 17 - 23; 1880 N. 3; 1881 N. 1-2; finalmente en el Revue archeologique de France. Paris 1878. Juillet, publicado en conjunto con A. Damour.

${ }^{6}$ Hamburgo por Otto Radde; Leipzig por Gustav Brauns; Yo basé mis datos en la escala pequeña de 6 marcos.

${ }^{7}$ Los números que están explicados mediante ilustraciones se indican en negrita. La procedencia de todos los objetos a partir de los determinados lugares de hallazgo es dada al final de este escrito.

${ }^{8}$ Ver: WEBSKY, Martin: die Mineralspezies nach dem spezifischen Gewicht u.s.w. (La especie mineral a partir del peso específico). Breslau, 1868, 4.

${ }^{9} \mathrm{~N}^{\circ} 22,23,24,25,26,27,37$ y 40 fueron descubiertas juntas en una misma tumba.

${ }^{10}$ N.T.: En el texto original se refiere a las localidades de la siguiente manera: San Cruz, Santana, Aqua Calientes y Los Palmares.

${ }^{11}$ Proveniente de esta misma área fueron enviados también algunos rodados de cuarzo en estado natural $\mathrm{N}^{\circ}$ 203, 204, 210, 273 (variedad blancuzca) y $\mathrm{N}^{\circ} 133$ ftanita negruzca. Estos no presentan ningún significado arquelógico a menos de que sean encontrados con piedras cortadas en sitos de sepulcros. ISSEL (Ver: Arch. F. Antrhropologie Bd. XIII, 1880, S. 174) encontró un uso de este tipo en tumbas en cavernas en Liguria, Italia. Lo mismo es válido para la $\mathrm{N}^{\circ}$ 176 , un pequeño fragmento no trabajado de ópalo noble que en América proviene de la Hacienda Esperanza en el estado de Querétaro en México, y distante a partir de DANA en Gracias a Dios en el estado de Honduras.

${ }^{12}$ Lo mismo cuando estos forman parte de una expedición.

${ }^{13}$ Yo me acuerdo de un relato del difunto Dr. A. v. Frantzius que practicaba como médico en Costa Rica, que contaba que una vez encontró, en la casa de un lugareño, un ídolo siendo utilizado ipara sostener una puerta! Con respecto a esto relata el Dr. Habel (comparación a mi presentación en el archivo para antropología 1880, vol. XIII, pág 148) de su viaje a Guatemala acerca del descubrimiento por suerte de las esculturas de Santa Lucía Cosumalhuapa cuando un día encontró que dos trabajadores de cantera estaban golpeando 
con cinceles una de las esculturas. Estos fueron contratados por el director de un cementerio para construir ahí una fuente. ¡Después de esto, él no tuvo otra alternativa que rentar el sitio por dos años para frenar la destrucción de estos tesoros arqueológicos!

${ }^{14}$ Rodrigues ha publicado hasta el momento (en portugués): Ensaios de sciencia por diversos amadores. I. II. Río de Janeiro 1876, 8. El cuaderno I contiene: Antiguidades do Amazonas; Armas e instrumentos de pedra pág. 93 - 125 con 10 lá- minas de ilustraciones. - Cuaderno II Arte ceramica con 13 láminas; luego en la misma revista 1879: Antiguadades do Amazonas pág. I-VI, luego pág. 23-125; I Armas e instrumentos con 10 láminas con explicación; II Arte ceramica pág. 1-23 y lámina 1-13 con explicación; III Atterros sepulchrales pág. 1-21; IV Sernambys pág. 23-24; V Inscripcões pág. 35-53 con un mapa y 5 láminas con explicación, finalmente: Observacões sobre os ceramicos do Para, pág. 57-74 y apéndices, pág. 75-79 con láminas VII-VIII. 


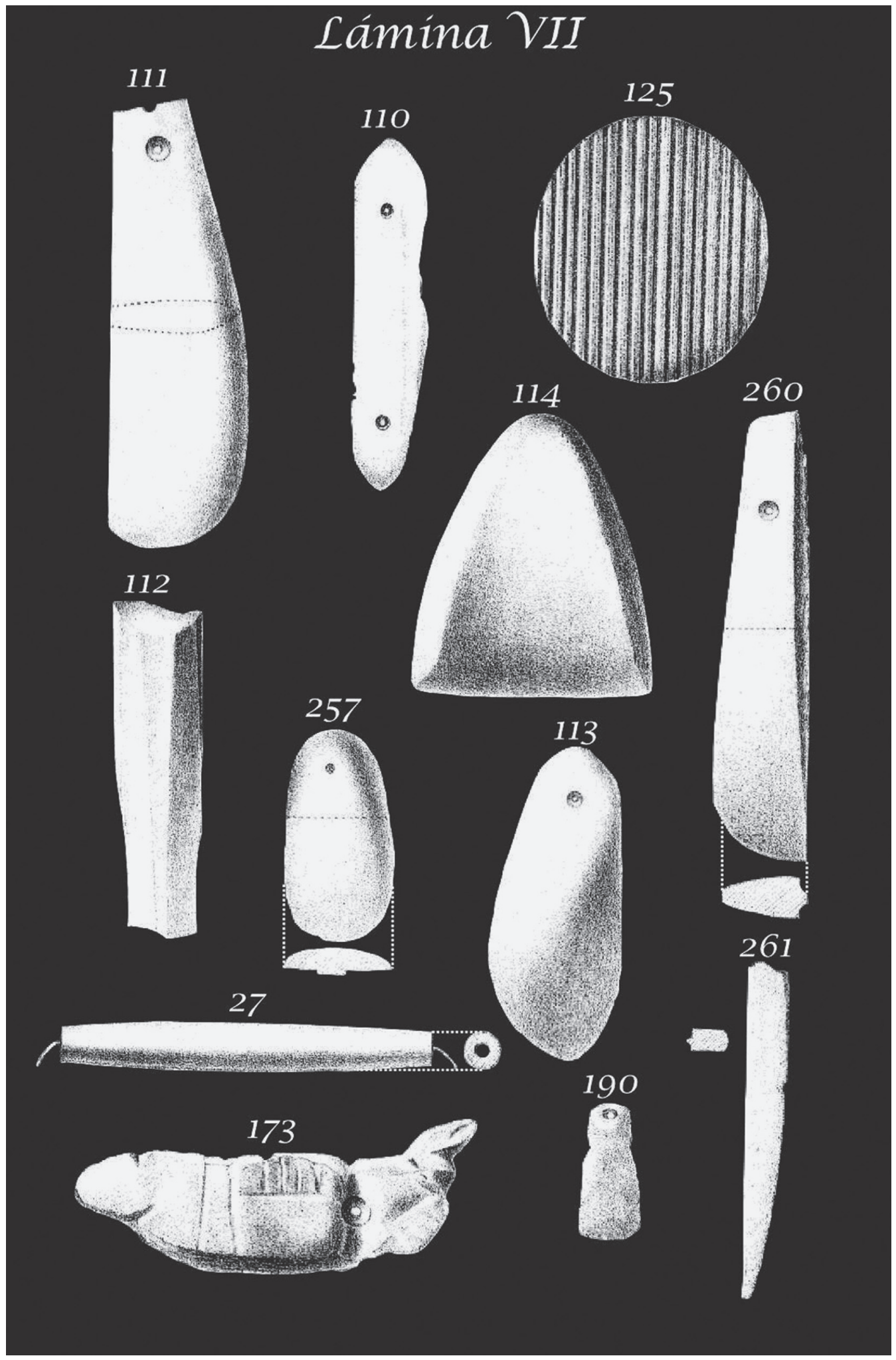

Revista Geológica de América Central, 37 Especial: 49-68, 2007 / ISSN: 0256-7024 


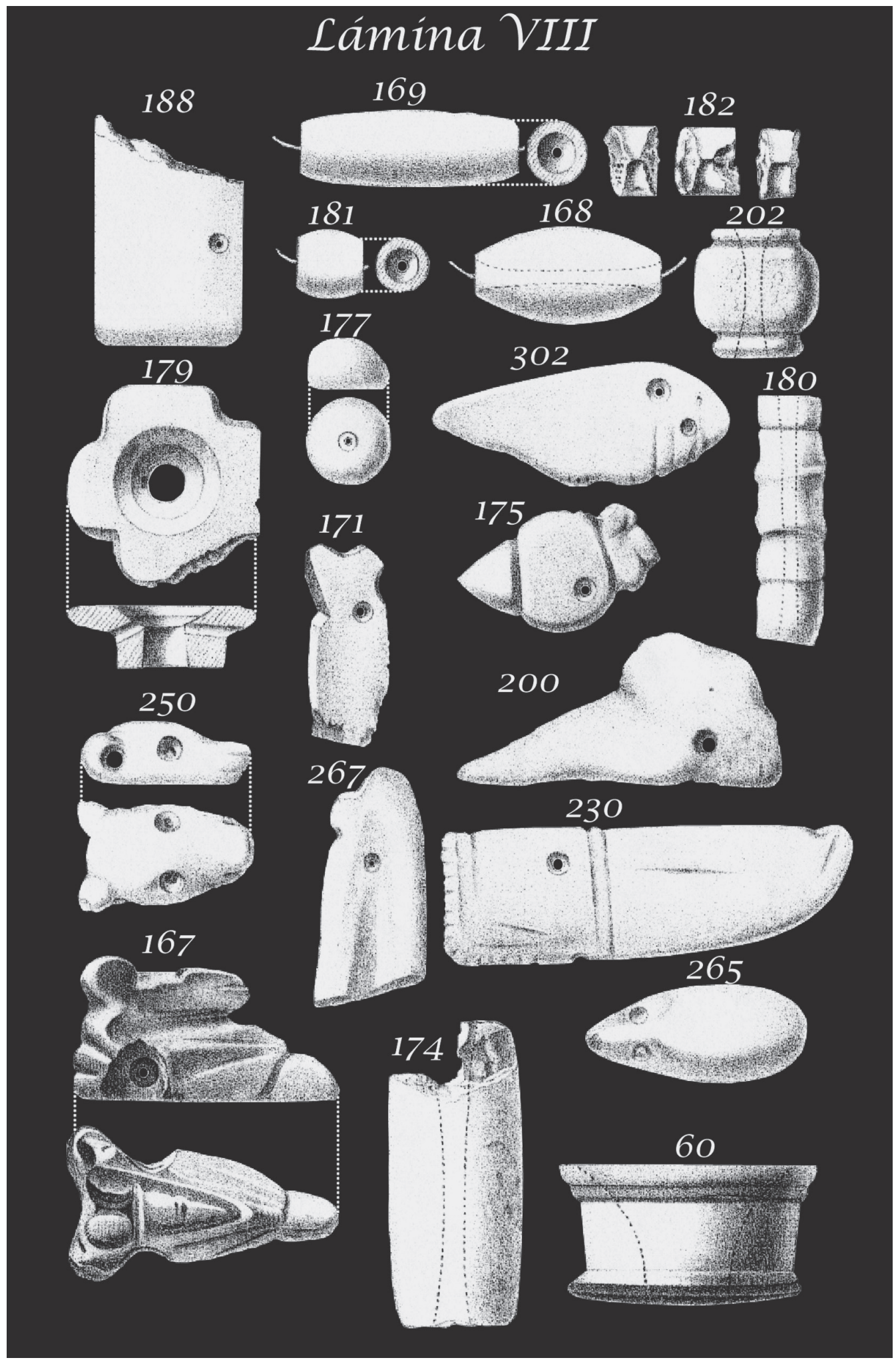

Revista Geológica de América Central, 37 Especial: 49-68, 2007 / ISSN: 0256-7024 


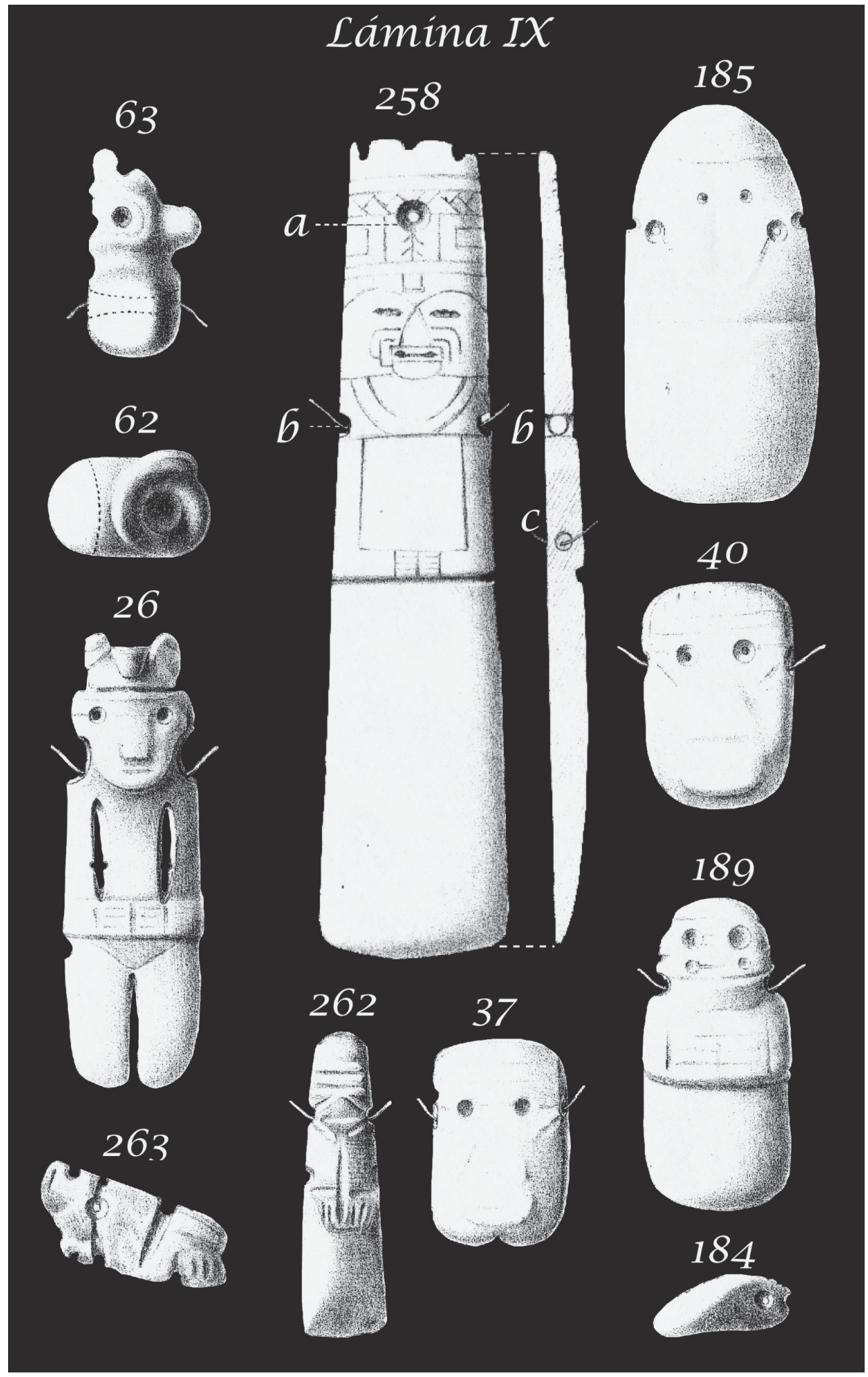

Revista Geológica de América Central, 37 Especial: 49-68, 2007 / ISSN: 0256-7024 


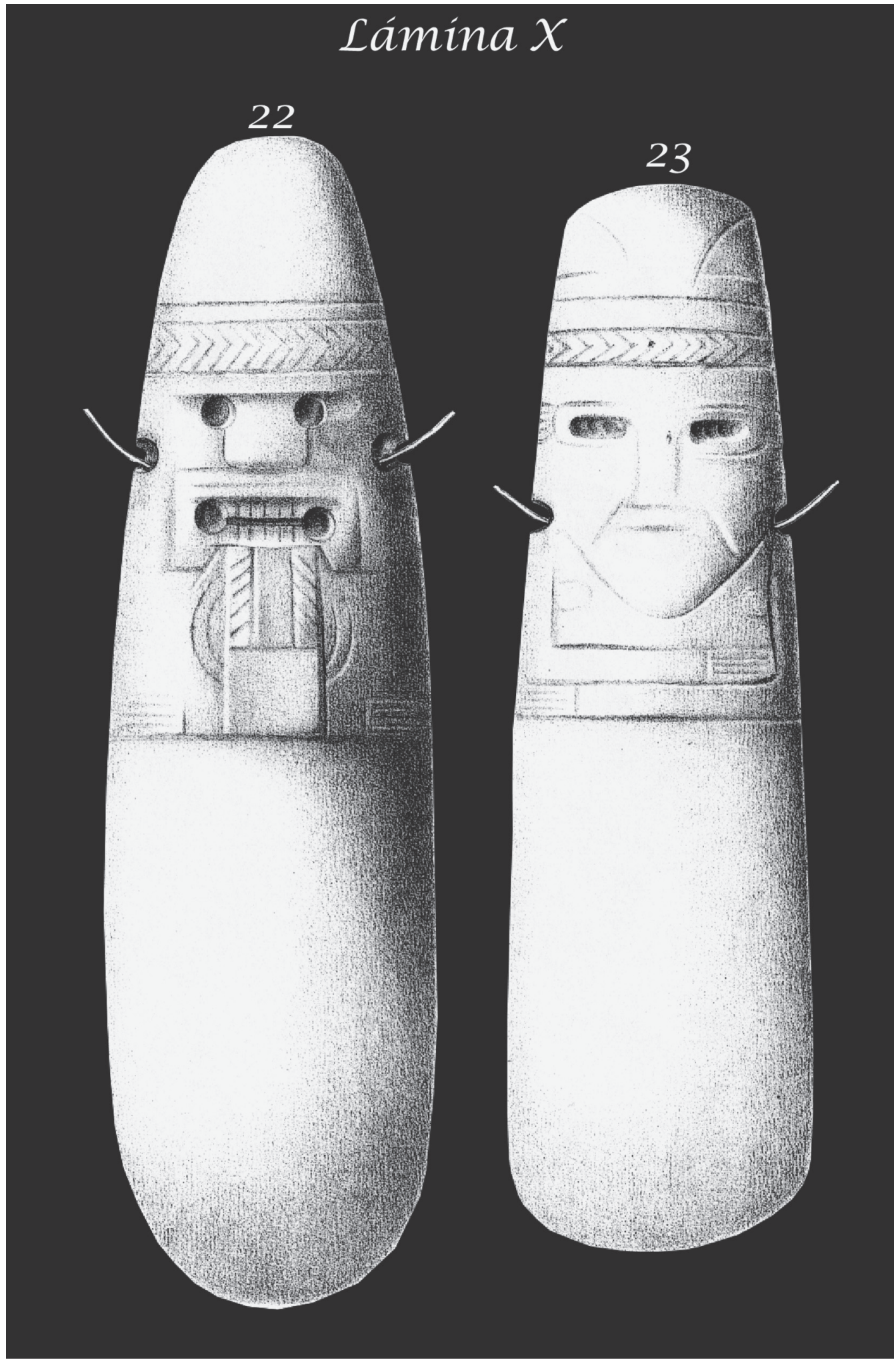

Revista Geológica de América Central, 37 Especial: 49-68, 2007 / ISSN: 0256-7024 


\section{Lámina $\chi I$}

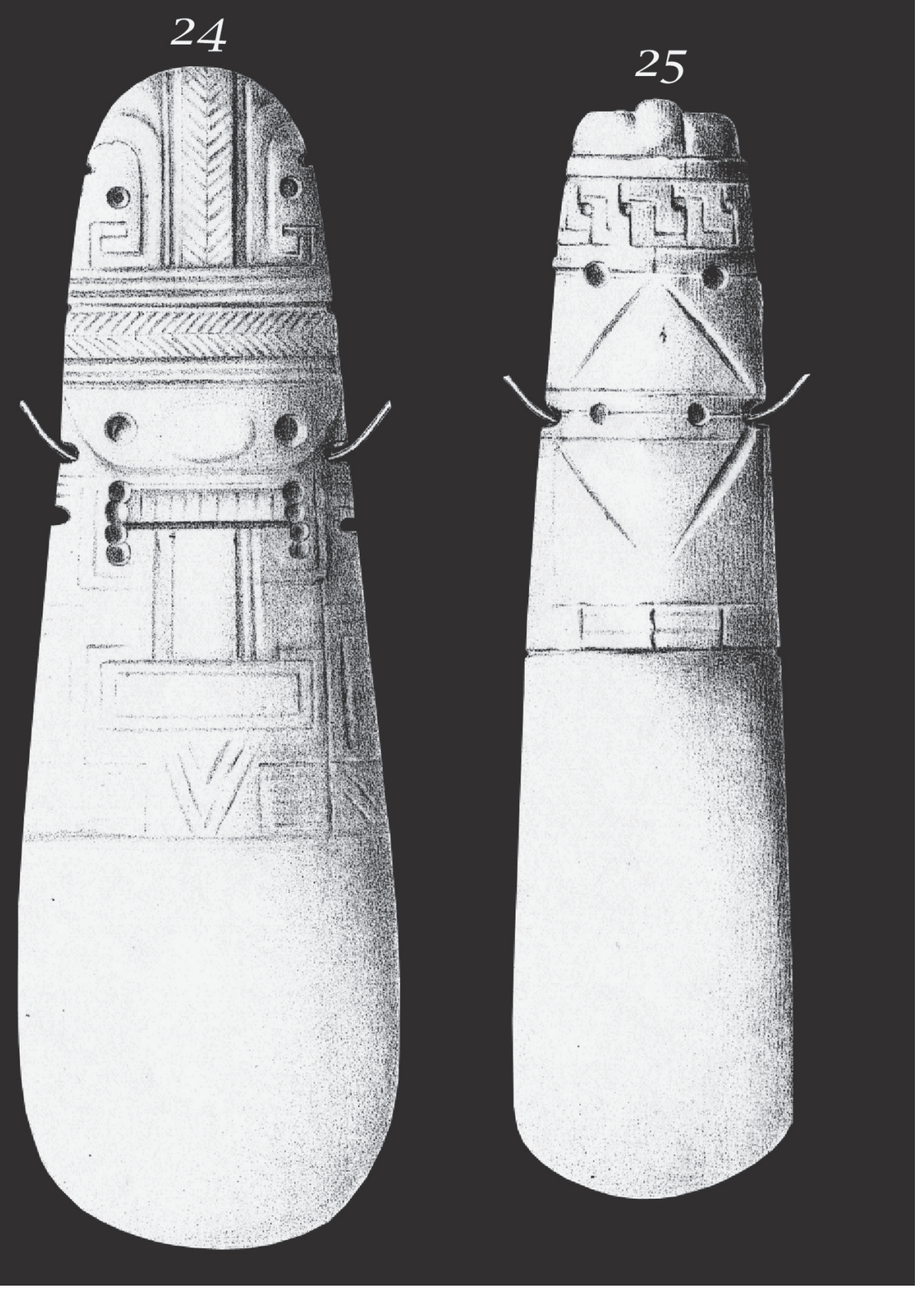

Revista Geológica de América Central, 37 Especial: 49-68, 2007 / ISSN: 0256-7024 